\title{
Measures and Safeguards to Realize Stable Poverty Alleviation in Contiguous Destitute Areas Based on Human Capital Development
}

- A Case Study of Xialatuo Village

\author{
Garong Nima \\ Southwest Minzu University, Chengdu, China \\ Email: 453043939@qq.com
}

How to cite this paper: Nima, G. (2019) Measures and Safeguards to Realize Stable Poverty Alleviation in Contiguous Destitute Areas Based on Human Capital Development. Open Journal of Social Sciences, 7, 70-84.

https://doi.org/10.4236/jss.2019.74007

Received: March 15, 2019

Accepted: April 9, 2019

Published: April 12, 2019

Copyright $\odot 2019$ by author(s) and Scientific Research Publishing Inc. This work is licensed under the Creative Commons Attribution International License (CC BY 4.0).

http://creativecommons.org/licenses/by/4.0/

\section{(c) (i) Open Access}

\begin{abstract}
Based on the perspective of human capital development, this paper explores the current situation and development of poverty alleviation in the three aspects of education, training, information resources and management organization according to the author's research in Xialatuo Village, Luhuo County, Ganzi Tibetan Autonomous Prefecture. The precipitation and rapid development of education is the fundamental factor for the stable and stable development of the village; The advantage of information resources reduces the gap between urban and rural areas and promotes the economic development of the village; The measures and implementation of organization and management guide the development of various aspects in the village and create a lot of development conditions for farmers. Finally, the author gives some suggestions on how to stabilize poverty alleviation.
\end{abstract}

\section{Keywords}

Human Capital, Poverty Alleviation, Xialatuo Village, Education, Information, Management

\section{Introduction}

In 1986, for the first time, the Chinese government distributed poverty reduction areas, determined and adjusted county-level supporting institutions for poverty alleviation and development and in total determined 331 national level poverty-stricken counties. In 1994, alongside with the formation and implementation of The 8 - 7 National Plan for Priority Poverty Reduction (a plan to assist 80 million people in having sufficient food and clothing within 7 years), the Central 
Committee of the CPC decided to increase the number of national poverty-stricken countries up to 592. Then, in 2001, to support the introduction of

The Outline for Poverty Reduction and Development of China's Rural Areas (2001-2010), all the poverty-stricken counties in eastern coastal areas were removed of such title, and the title of national poverty-stricken counties was transferred to counties in middle western underdeveloped areas, which maintain the total number of 592. Therefore, in 2011, present contiguous destitute areas came into being. On the press conference about The Outline for Poverty Reduction and Development of China's Rural Areas (2011-2020), the State Council, for the first time, proposed that we should regard contiguous destitute areas as the chief battlefield in poverty alleviation campaign and promote it up to a national major strategical measure. The Outline lists fourteen contiguous destitute areas. General Secretary Xi Jinping has pointed out that poverty alleviation work has already been to the tough stage that "we have to bite the hardest bones and achieve success", and those hardest bones refer to those fourteen contiguous destitute areas mentioned in The Outline. To achieve the goal that China will build a moderately prosperous society in an all-around way in 2020 , we should emphasize the middle western districts and the difficulties lying in those contiguous destitute areas. Basically covering most poverty-stricken areas and deeply impoverished population, contiguous destitute areas can't develop just by the driving force of general economic growth, neither do the regular poverty alleviation methods work, which indicates the extreme difficulty in poverty alleviation and development. Therefore, we need further efforts to intensify our measures to implement poverty alleviation programs in contiguous destitute areas. As the well-known economist Thodore W. Schults found, some countries with poor natural resources (such as Switzerland and Denmark) accelerated their economic growth after World War II. In some developing countries, even with the same material assistance, their development speed is still not satisfactory. Schultz led the study of this phenomenon. He pointed out that traditional economic theory holds that economic growth must depend on the increase of physical capital and labor, but this cannot explain all the factors of productivity improvement. Statistics since World War II show that the growth of national income is much larger than the growth of national resources input. Therefore, he believes that an important factor is at work but is ignored. This factor is human capital.

It can be seen from his research results that the key to the development of Ganzi Tibetan economics is to solve the problem of lack of human capital, human capital development as a radical measure to alleviate poverty has a continuous and decisive role in the development of all aspects of the region. The region will achieve a sound and rapid economic development, help the poor to achieve increased income and self-development capabilities, realize the comprehensive well-off is completed as scheduled and truly out of poverty after the goals of sustainable development to provide strong protection. 


\section{Literature Review and the Choice of the Area to Study}

\subsection{Literature Review}

From the beginning of targeted poverty alleviation program to the $18^{\text {th }}$ National Congress of the CPC when General Secretary Xi Jinping firstly put forward the goal of construction of moderately prosperous society in all respects, targeted poverty alleviation from the central government to local governments has encountered severe obstructions in deeply impoverished areas, and effective poverty alleviation work and guarantee in contiguous destitute areas have aroused studies in academic circle from different directions and angles. Based on timeline from the year of 2012, the writer teases out relative literature and studies: Liu Xiaolong, et al. (2012) studied how to alleviate poverty in Nujiang prefecture, Yunan province through the combination between reality and the Outline. Tang Yong, et al. (2013) studied the development mode of poverty alleviation and development in contiguous destitute areas through tourism industry by the case study of Qinba Mountainous Area, Sichuan province. He Wenhu (2013) studied the financing mode of infrastructure construction in contiguous destitute area and put forward some advice. Li Xian'e, et al. (2013) studied how to conduct economical poverty alleviation in contiguous destitute areas. Liu Xiaopeng, et al. and Yang Long, et al. (2013) studied the poverty measuring in contiguous destitute area. Sheng Maoying (2015) took Tibetan areas of Sichuan province as a case of contiguous destitute areas to analyze difficulties faced in the targeted poverty alleviation in Tibetan areas of Sichuan province. Li Jia (2015) took Tibetan areas of Sichuan province as a case of contiguous destitute areas to make a quantitative analysis on the discrepancy of tourism economy among 10 prefectures in those areas. Zhang Xiang (2016) held the opinion that education is the fundamental measurement to alleviate poverty and he put forward advice on the establishment of game model on poverty alleviation through education, and construction of supervisory mechanism to ensure precise recognition, operation and assessment. In 2018, research group from Party School of the Central Committee of CPC took Luliang Mountainous Area as an example to have studied its high-quality and sustainable poverty alleviation mode in order to discuss the poverty depth, effective grasp of poverty alleviation policy and the feasibility of its implementation.

\subsection{Choice of Research Object}

According to the above literature, the academic circle has made studies mostly on theoretical studies including the targeted poverty alleviation's connotation, difficulties, reasons and measures, yet as for studies on concentrated contiguous destitute areas mainly involve poverty depth, poverty alleviation through tourism and education and etc., we could hardly see studies on the integrated combination of different modes of poverty alleviation, and there is almost few study on field research or based on economical data about relatively small administrative region such as township or village. Therefore, this thesis made Xialatuo vil- 
lage, Luhuo County, Ganzi Tibetan Autonomous Prefecture as its research region. First of all, this research chooses Ganzi Tibetan Autonomous Prefecture (hereinafter referred as Ganzi Prefecture) because it is facing a relatively severe situation compared with other Tibetan areas of the four provinces in poverty coverage, poverty depth and economically difficult population. Ganzi Prefecture covers a vast territory, which is 30 thousand square kilometers lager than that of Fujian province; it has 1.1649 million permanent resident population, and its destitute population is more than any other prefectures in Sichuan Tibetan areas. Natural condition, living environment, education, medicare and regional culture contribute to its high re-poverty rate and conspicuous phenomenon of regional poverty and inter-generational transmission of poverty. Due to the fact that Ganzi Prefecture administers 18 counties and cities, it possesses high extent of homogeneity and heterogeneity within the prefecture. Homogeneity is reflected by traditional culture, religious culture, industrial structure and the like, while heterogeneity means the differences of custom and life and production style between different areas caused by huge disparity of landform. Moreover, Tibetan dialects vary in different places, and views and values of those who live in agricultural areas are different from that of those who live in pasturing areas. Both the homogeneity and heterogeneity harden poverty alleviation and elimination, but meanwhile, they provide us with powerful supporting point of poverty alleviation development by adjusting measures to local condition. Therefore, the writer chooses Ganzi Prefecture as the research area.

The specific research area is located in Xialatuo Village, Luhuo County. The writer chooses this village because of the following three reasons: firstly, it is suited in the central region of the Tibetan area in Ganzi Prefecture, and it shows high level of ethnic integrity because it maintains traditional Tibetan culture, and also absorbs external culture because the Fourth Front Army once stationed here for a period. It is nice dealt with such situation and the effective and harmonious development could provide valuable lessons for other ethnic areas in the era of culture shock and integration; secondly, it is a typical region which boast high utilization ratio of human capital, which can be reflected by many aspects including population structure, diversification of family income, education background of the whole village, villagers' acceptance of new production technology and new science and technology, and the influence of traditional religion on villagers. Inequality between generations gives rise to underdevelopment of human capital, which could reversely prove that the human capital development of Xialatuo Village ranks the front line of Tibetan destitute areas. Compared with other Tibetan areas in Ganzi Prefecture, it enjoys sound economic structure, whose optimization is limited by the natural resources of a region and, more importantly, decided by the value structure of local human capital. One of the important parts in economic structure optimization is to optimize industrial structure, which needs the driving force of human capital as well. Improvement of the value of human capital is the impetus of industrial structure. 
Thanks to favourable impetus, the village could develop its economy, surpass and distance itself from surrounding areas.

The third is the fact that although located in the central region of the Tibetan area in Ganzi Prefecture where exists extreme poverty, large destitute population and vast poverty territory. Xialatuo Village has basically achieved moderately prosperous lives all over the village, and villagers here earn much more than farmers and herdsmen of other villages in Tibetan areas. Conspicuous contract in economy and social development can be seen between this village and other Tibetan areas.

In conclusion, it is not only of profound and far-reaching significance on the measures and guarantees to alleviate poverty in contiguous destitute areas in Tibetan areas and even the whole ethnic areas, but also could provide perspective anticipation and referential value on the economic and social development in contiguous destitute areas after they get rid of poverty and live a moderately prosperous life.

\section{Background Introduction of the Research Area}

Located in north central Ganzi Prefecture and north on the Xianshui River, Xialatuo is administered by Luhuo County, Ganzi Tibetan Autonomous Prefecture. It is 17.5 kilometers away from Luhuo County with an altitude of 3070 meters. It possesses four working teams with 123 households of the population of 529; school-age children enrollment rate here is 100 percent, and family planning rate reaches 100 percent. Its forest land covers an area of more than $18,000 \mathrm{mu}$ (=1200 hectares), and its grassland covers an area of $15.636 \mathrm{mu}(=1042.4 \mathrm{hec}-$ tares). Its arable land covers an area of $2457.5 \mathrm{mu}$ ( $\approx 5163.8$ hectares) (among which land circulation area is $2130.8 \mathrm{mu}$ ( $\approx 142$ hectares). Places planted with lilies cover areas of $820 \mathrm{mu}$ (around $\approx 54.7$ hectares), Zang Qing No. 2000 highland $200 \mathrm{mu}$ ( $\approx 13.3$ hectares), wormwood $500 \mathrm{mu}(\approx 33.3$ hectares) and cole with $610 \mathrm{mu}$ ( $\approx 40.7$ hectares). "Xialatuo" means grassland for sika deer in Tibetan language, and it is told that this is the place where gold deer lead a flock of deer playing around. It is more than a place where Han and Tibetan cultures integrate, and it is also the end point where western culture entering north towards Kham Tibetan areas. Integration and improvement of various cultures formulate unique social culture in Xialatuo Village. It was once the main place for the Red Army to adjust and get gathering during the Long March in Tibetan areas, and it sheltered and protected the most wounded soldiers from the Red Army among other villages, which contributed to its high level of openness and inclusiveness. It is also an important high-quality highland barley commodity grain produce base in Luhuo County, and it has long been praised as "the Granary of Luhuo County". Xialatuo Gold Deer Breeding Association once received the title of Advanced Group of Scientific Popularization granted by Science and Technology Association of Ganzi Prefecture. In 2017, the village was granted with titles such as the Top 100 Villages of Sichuan province, provincial-level "Four Goods Village" (which means people live in good house, lead good lives and develop 
good habits, and the society is of good atmosphere), national civilized township and others. During the research and survey, the writer finds that Xialatuo villagers keep no resistance and rejection against external cultures, they all spare no effort to combine Tibetan culture with Han culture and others, and they have formed their own characteristics. Thanks to the integration and mutual-improvement of various cultures, those villagers have formed the produce and life custom that they are willing to innovate and show no timidity toward experience. Long time cultural immersion in the history makes its administrators have always devoted themselves to establishing the philosophy of "paying high attention to education and being honor to get the involved in school" in the whole village, which turns the village into a "study-oriented" village where villagers receive more education and are more able and more willing to accept new things and new ideas than those of other Tibetan areas. In the highland village, every household is equipped with television receivers, televisions and computers. The percentage of households who have installed program-controlled telephone has surpassed 60 percent. The number of households who make a living by delivery has reached 55. Meanwhile, the village has cultivated private entrepreneurs known inside and outside of Ganzi Prefecture.

\section{Analysis on the Reasons of the Development of Xialatuo Village}

The writer will not say more details about its development fruits. Xialatuo Village is located in snow-capped plateau, and it is the place where Tibetan ethnic groups concentrate and most people here believe in Tibetan Buddhism. Its economic development mode and development experience could offer multiple possibilities when we face difficulties in the fight against poverty in Tibetan areas and even the whole ethnic areas. Therefore, in-depth analysis and comprehensive conclusion of "the Xialatuo Mode" is of great significance and far-reaching meaning. Through the research and survey in Xialatuo Village and the collection of different materials, the writer sums up the following reasons:

\subsection{Education and Training}

Investment in education is an important part of human capital investment. It is the characteristic of the economic benefits of investment in education that educational investment is long lasting, which means that its economic benefits last for a long period, rather than a short period. Once workers have received basic knowledge, theories and skills, they can play a part in production during their whole labor age unless they lose their labor capacity. Moreover, through education, workers' developed intelligence and capacity to analyze and solve problems could work for a longer time [1]. It is necessary to analyze investment in education, a long lasting investment in human capital, and its combination with the educational history of Xialatuo Village. Early in 1906 (i.e. Guangxu's reign in the Qing Dynasty), French missionaries established a catholic church in the village, 
which lied in the northeastern hillside field of the village. They started classes to teach doctrines and taught in Tibetan language, English and Chinese. That was the first time of Xialatuo villagers to receive formal education, and it initiated educational industry in the village. Then, in the late Qing Dynasty, General Zhao Erfeng arrived at this place at war. In response to the call of "bureaucratization of native officers", some soldiers married local Tibetan people and stayed here ever since. Most of those are renowned and intellectual men who then played important roles in the development of local education and society. There were only three official schools established by the Qing government in this region, and their propel made it the reality to build one in the village. The establishment of official school has constant influence on the educational development of the village. During the Agrarian Revolutionary War, the Fourth Front Army stayed in Ganzi Prefecture for almost half a year, and Xialatuo Village also maintained some soldiers. In fact, it received the most soldiers for the longest time among all the villages in Ganzi Prefecture. Villagers maintained a great number of wounded soldiers, and those soldiers then stayed here permanently, so did their culture, knowledge and ideas. Those soldiers encouraged their and other villagers' children to go to school, and many of them became the managers of the village. They adopted a series of effective measures to encourage the educational development. There still lived Red Army soldiers in 2017. After the foundation of new China in 1949, the catholic church was transformed into a school building, and the government of Luhuo County established Xialatuo Elementary School. Thanks to the long time accumulation of educational investment and the cooperating efforts of all the villagers, the number of students in the village keeps growing, and its educational level is advancing. Xialatuo Village gradually took the leading role in Luhuo County in education and the situation has remained the same until now. In 1970, Xialatuo Village became the first one to start a junior high school to link the preliminary school to high school in the administrative village, which indicates its desire for higher quality educational resources. Since the start of Reform and Opening-up, village-level preliminary schools including that of Xialatuo Village have enjoyed better conditions for school operation and better educational resources with the attention of the government to education and the increasing resources invested in education. It then started a preschool to enable children under school age could receive education in advance. At present, all the school-age children in Xialatuo Village go to schools and none goes to the temple. Consolidation rate of school students and enrollment rate here reach 100 percent every year. Due to such educational environment, this village has cultivated more than 240 talents taking positions in government administrative departments, enterprises and public institutions, and more than 100 private entrepreneurs. "Hometown complex" in turn encourages them to contribute to the development of their hometown, and there emerges a positive cycle. And this is one of those important reasons for which the development of Xialatuo Village has been constantly speeding up for the past ten 
years. Early in 1988, from the human capital accumulation and development mode in the thesis On the Mechanics of Economic Development, Lucas concluded that spillover effect of human capital will improve the productivity of all the production factors and then the output would have incremental effect [2]. Yet situations in Xialatuo Village are better. During the research and survey, the writer finds that workers of the village get more than formal or informal education from those talents who are cultivated by the village and work outside. Those who take leadership position in government administrative departments, enterprises and public institutions have more or less won preferential state policies in all aspects for their hometown. For example, the village-level activity room in Xialatuo Village was financed by the government under the approval of leaders of Ganzi Prefecture when they were invited to take part in a festival activity here; when other villages were equipped with no fixed-line telephone, Xialatuo Village became the pilot village of a government-invested project, and every household was equipped with satellite televisions. It is no doubt that convenient access to external information largely propels its overall development. In short, there are many alike examples, and depending on leaderships cultivated by the village, Xialatuo Village has received various degrees of preferential policies and project supports covering infrastructure construction, investment in educational resources, agricultural modernization, information construction and etc.. Looking back inside the village, the writer finds that Xialatuo Village is the example of national unity because the influence of historic culture and the reality of integration of multiple ethnic groups. Besides, due to their better educational background, higher ability to accept and utilize new things and new science and technology, those government-invested projects tend to be successful here. No wonder that Xialatuo Village attracts more attention from government preferential policies and pilot projects, and it develops more fiercely. Meanwhile, private entrepreneurs cultivated by the village also bring benefits back, and the spillover effect of human capital becomes more distinct. They bring back to Xialatuo Village new production technology, production philosophy, managing philosophy, and capabilities to find jobs and become rich from advanced areas. They teach those to villagers, and because they are themselves villagers of Xialatuo Village, they have more advantages than other people in communication and relationship, and as a result, those philosophies and skills can be learned and used by those villagers quickly. Those "Xialtuo people" who are assumed with leadership, cadres and entrepreneurs in all fronts return to the Village now and then to care for the development of their hometown, support its construction and devote themselves to their hometown. Those talents cultivated by the village return to care for and support this village. Besides, their success, career and prospect inspire villagers a lot, and more importantly, give strong push to those teenagers who are studying and growing up. Meanwhile, it also propels the imperceptible rules for the village to pay attention to education, honor knowledge and cultivate talents. It has been 112 years since those missionaries established the catholic 
church to start the first formal education in 1906. Educational philosophy of Xialatuo villagers has stayed the same throughout the 100-year changes involving the changes of dynasties, War of Resistance against Japanese Aggression, and Cultural Revolution. It is the fundamental reason for the village's positive development that education could propel the development of an area.

\subsection{Information Resources}

The writer has mentioned above that Xialatuo Village has various accesses to information. Several years ago, in-village broadcast, television and the Internet covered the whole village, and villagers are familiar with the utilization of those facilities to get various and mass external information. Moreover, they can gain much political information from villagers who take positions in system, and market information from villagers who are private entrepreneurs or those who work outside the village, all of which constitute importance factors to develop the village. Being a sort of resource, information, refined and analyzed by the brain mental activity, could be mastered by people. People having mastered information could turn its hidden energy into fortune through rightful utilization [3]. Through the research and survey, the writer finds that Xialatuo villagers are familiar with how to turn information into fortune. They are much more able to analyze, unify, utilize and share the process to turn information into fortune than those of other areas, which is benefited by the fact that almost every family has a relative who work in government administrative departments. Therefore, they are outstanding in dealing with information. Compared with other resources, information possesses unique characteristics: the first is sharing nature; the second is time-validity, which means that information can be effective only in proper timing. The third is dynamic nature, which means that information is dynamic, enriching, and growing. The fourth is inseparable nature which means that it is inseparable in the production process; the fifth is non-identity, which means that information, when regarded as resource, is different from each other. The sixth is dominant nature (i.e. controlling nature), which means information is able to develop and control other resources [4]. An occasional talk with a villager during the research and survey could indicate the Xialatuo villagers' control of the characteristics of information: a young villager told an elder villager that he was intended to repair his side room in order to rent it to travelers as homestay, but he couldn't get materials to repair the room because the government forbids people from cutting down trees. The elder said that he had heard that Forestry Bureau would issue a policy that if farmers and herdsmen were going to arrange marriages or funerals, they can hand in applications to cut down a set quantity of trees in cutting sections. He also said that he could ask for more information because his nephew worked in Forestry Bureau. After he had made a call, the elder said to the one who need to repair his side room that this policy would be in effect after September. The young one said that his brother would get married in the second half of the year, and he then could make use of 
this opportunity to apply for cutting down trees to the Bureau. This example indicates Xialatuo villagers' control of the sharing nature, time-validity, and dominant nature of information. It is exactly the ability to refine and transfer such information that pushes the development of the village's society and economy. Meanwhile, informatization level is closely bounded with villagers' information consciousness and information ability. Thanks to the fact that Xialatuo villagers generally possess higher education background, and earlier access to the Internet, they are familiar with how to obtain and refine useful information on the Internet, which intangibly improves their control of information involving public services, services for the convenience of people, e-commerce and training experience, resulting in the breakthrough of the information gap between city and countryside. It also improves villagers' quality to take advantages of the Internet and e-commerce, and propels the development of "Internet Plus" model of agriculture, which then constantly pushes the upgrade and integration of products from the first, second and third agricultural industries, and its development.

\subsection{Management and Organization}

Community management, administrative management and organization in rural areas constitute significant parts of rural development, and proper organization and management could yield twice the result with half the effect in rural development. China's rural administrative management mainly consists of village party branch and village committee, besides, oversight committee of village affairs would supervise the management power usage of the two committees and village cadres. However, in rural areas, proactive economy and social development depend on more than just organized administrative management, they also need people-oriented rural community management to local conditions. Managers of Xialatuo Village fully recognize it, and they adopt different management methods to ensure the development of various aspects. They guide villagers develop society with harmony and stability by introducing the development of good social morality. Since the year of 2003, the village has held large collective celebration activities every year to celebrate the longevity of the elders, and they will give present to those elders. Meanwhile, they will select filial children and harmonious family during the activity, and those winners will receive some money as prize. The prize does not worth much money, but villagers honor those prizes, and it is no wonder that such inspiration mode provide the development of all careers in the village with stable and harmonious social environment, which is the precondition of the development of all careers. It also grants villagers more opportunities to conduct external exchange and circulation, because power against social stability would inhibit people's exchange [5]. Therefore, social environment of Xialatuo Village lays foundation for the development of both households and the whole village; village collective also guide villagers to benefit each other in economic development, and they let villagers learn knowledge on agricultural technology, how to use modern agricultural equipment, 
and guide them to actively learn production skills and how to find a job. Those Managers urge villagers diversify their income sources, and educate villagers with cases from both positive and negative side. Different form cities, rural areas meet more difficulties in changing a career than in reforming existed operation [6]. Although village managers might not understand it thoroughly or from a macro view, they can conclude from real lessons that diversified income sources could relieve the harm when households encounter natural disasters, illnesses or other impacts. Therefore, village collective will evaluate every household regularly and elect "Xialatuo Expert in Getting Rich". Those "experts" will then share their approaches to getting rich and stories for other villagers' reference in village collective events. Such mode that people from the same village told about things happening around has helped many villagers on the way to get rich because they find their own way to get rich by taking example by other people's success. The whole village also takes positive guidance of villagers and school students in education. During my research and survey, secretary of the village party branch said that, "I am determined to make the primary education in our village keep pace with education in other places, thus, we can make our children keep pace with the outside world." It is the same as the saying of Mr. Fei Xiaotong, a socialist, that education must keep pace with reform [7]. Since the year of 2001, Xialatuo Village has granted award and financial support to excellent students every year. This year, in the activity to celebrate harvest, village collective grants more than ten excellent students financial support varying from 300 Yuan to 1000 Yuan, and give them awards. The whole village constantly consolidates the village motto that "education is priority, reading is honor". Seen from years of accumulation, those managing measures do take effect. At present, those students who have received such honor are praised by all the villagers, and they become examples for other school students to study hard, which is the perfect reflection of such measures. Besides, organization itself is a sort of capital, and managers of Xialatuo Village are themselves a sort of organizational capital. Through constantly update and development of organization and management, the village maintains its harmony and stability, guides its villagers to develop in all respects, and provides villagers many opportunities to develop, which is one of the important reasons of its prosperity.

\section{Advice on Measures and Safeguards}

Through analysis on why Xialatuo Village develops so well, and in accordance with commonness of Tibetan areas and even all the ethnic areas, we could come up with many thoughts and inspirations. In the light of the development experience of Xialatuo Village, the writer holds the opinion that measures and safeguards to relieve poverty of contiguous destitute areas can start with the following aspects:

\subsection{To Change Ideas by Education and Training}

In order to change herdsmen and farmers' ideas, the first thing is to change the 
ideas of the government departments and relevant administrative officers. For a long time, governments of ethnic areas pay too much attention to the lack of natural resources and capital stock, yet they ignore the enormous economic benefits brought by human capital, and this phenomenon become increasingly obvious in basic level governments. Theory on human capital indicates that more investment produces larger high-quality population, and better social and personal benefits, but since such investment has long-term effects, it requires far-reaching development prospect of the government. Human capital is the product of investment in education, and the theory on returns to investment in education proposed by Psacharopoulos indicates that the lower the economic development level an area is at, the higher the returns rate will be [8]. Therefore, we should take gradually change ideas of farmers and herdsmen through the following methods: the first is to ensure the enrollment rate of students of nine-year compulsory education; the second is to intensify investment in order to balance education level in different areas; and the third is to implement useful and practical professional and technical training.

\subsection{To Perfect Talent Market and Rationalize Talent Flow}

Faced with a large amount of surplus labor force and extremely low utilization rate of talents, local governments should make it fundamental that they need to realize the revitalization through talents, and make it the key problem to take proper and flexible advantages of talents. The theory of human capital has pointed out that population movement or migration is one of the ways to increase human capital. The $19^{\text {th }}$ National Congress of the CPC also makes it clear that we need to eliminate disadvantages in system and mechanism that inhibit the flow of labors and talents. However, many local governments in western ethnic areas tend to impose compulsory restrictions on talent movement, thus, some talents, for the fear that they might be restricted, are hesitated to go to ethnic areas, while those who have already taken positions in ethnic areas are left unused, and their capacities are wasted, which is a distressing loss of talents and their intelligence. In some places, local government organizations and private institutions lack or violate fair competition in recruitment, and those talents lose their hope and then, driven by economic benefits of advanced areas, choose to leave ethnic areas, which forms the disadvantageous situation of brain drain. Restricted by the system limitation of household registration, land and other things, rural surplus labors find it difficult to output their labor effectively. Therefore, it is of top priority that the government should put down inhibitions on reasonable movement of talents, establish fair competitive mechanism of human resources, and reform the disadvantages in mechanism that inhibits the movement of rural labor force.

\subsection{To Reinforce Medical Security}

In accordance with the theory of human capital, the amount of human capital is 
decided not only by the education background of population, but also by the health level of the population, because good health could ensure population productivity. Therefore, the $19^{\text {th }}$ National Congress of CPC proposes that we should increase basic medical insurance and serious disease insurance protection for rural and non-working urban residents, which is of great significance for the development of human capital in western ethnic areas. Health issues exist in many places in China's western ethnic areas because, on the one hand, the majority of people have unhealthy living habits for the lack of hygienic knowledge due to their low level of education; and on the other hand, medical institutions are rarely seen in ethnic areas, and the employees here are not of high quality, and medical devices are not so good here. The poor health of population directly causes the slow development of economy, and some places even see negative economic growth. Therefore, at present, we should, for one thing, intensify the training of rural medical employees and the construction of village-level clinics; and for the other, we should give attention to cultivate the medical employees. The above two points, combined with new basic medical insurance and serious disease insurance protection for rural and non-working urban residents could help to develop economy by increasing the quality of human capital.

\subsection{To Strengthen Endogenous Power}

Endogenous growth theory proposed by Lucas has pointed out that the communication of knowledge and human capital brings about "catch-up effect". Traditional economic theories hold that the growth of national income keeps pace with the growth of resources consumption. But the fact is that the growth of national income is far more than the investment in material capital and actual labor amount [9]. This discrepancy comes partly from the benefits brought by scale effect, and partly from the benefits of the improvement of quality of the investment in human capital. These years, industrial structure adjusting has become a cliche, but how to adjust rural industrial structure still has no clear answer. From the above theory, the writer thinks that local governments should start with the comprehensive mobilization and intensification of the endogenous power of rural population. Seeing from some small enterprises in ethnic areas who have successfully integrated the first and third industry, we can infer that those that were regarded as natural and cultural disadvantages can be turned into advantages, and can bring about beneficial effects. Meanwhile, those successful enterprises possess strong endogenous power as their common feature. The government should invest to conduct in-depth analysis of every factor behind the success, and then apply those research results reasonably to other farmers and areas, carry out, mobilize and improve the endogenous power of population in ethnic areas in large scale in order to inspire their hope to get rich and develop, and then give right guidance of their development direction and approaches. Besides the improvement of economic development and industrial integration, starting up private enterprises can also give resolution to the issue that govern- 
ment undertake the single responsibility to transform human capital, and solve the structural employment contradiction of rural population.

\subsection{To Adjust Local Educational Structure}

First of all, we should implement compulsory education and ensure investment in basic education. Basic education is featured in small investment and high benefits. Although Ganzi area has already implement nine-year compulsory education, poor conditions of school operation and lagged school facilities make up the current situation of basic education in ethnic areas. The government should ensure and increase investment in basic education, improve conditions of school operation, enhance the teachers' earnings, change educational ideas, and strengthen the foundation of local human resources. In addition, the government should upgrade educational structure in order to build educational system to develop human resources suitable to the area development. Since the quantity of institutions of higher leaning are relatively small, local governments should encourage and attach great importance to the introduce of education of local institutions of higher learning into local economic development. They should cultivate pragmatic talents for the local economy by the setting and planing of specialized curriculum. They should constantly update educational structure and ensure its perfection through planning of vocational courses and cultivation mode of institutions of higher learning. Judging from current economic development of Ganzi Tibetan Autonomous Prefecture, including vocational and technical institutions, institutions of higher learning need adjustment on disciplines and majors as soon as possible, and the adjustment should particularly conform to local economic development and cultivate skill-oriented talents in tourism resources and product development, development of water resources and mineral resources, market development and economy and trade.

\section{Conclusions}

The process of how rural residents' own knowledge, skills, health and other human capital can realize their value in economic activities is closely related to political system and social culture. The diversity and difference of cultural knowledge and production skills in minority areas are related to geographical location and natural conditions. To have a clear understanding of how knowledge, skills and other human capital connotation affect the poverty alleviation work in the rural areas of ethnic minority areas, we must have a clear understanding of the status quo of the development of ethnic minority areas and the role of education, information, skills and other human capital investment in this region, and have a full understanding of the diversity of human development and the diversity of employment. This paper studies the relationship between human capital and poverty alleviation through field investigation and analysis of poverty alleviation work in Tibetan areas of Sichuan.

On the one hand, the improvement of rural human capital can release more 
agricultural resources, provide more free space for the scarce agricultural production means in Tibetan areas, improve agricultural productivity, and on the other hand, promote the development of secondary and tertiary industries. The improvement of human capital of rural population in ethnic minority areas is an indispensable part of enhancing the self-development ability of poor peasant households and sustainable development after the building of a moderately prosperous society in an all-around way. Moreover, with the improvement of the human capital stock of non-agricultural workers in Tibetan rural areas, it can promote the formation of high-quality rural labor force, and can directly and effectively reduce the cost of urban management in migrant areas. Therefore, it is of great significance to explore how human capital affects the cause of poverty alleviation in Sichuan Tibetan areas, and how various human capital factors affect Sichuan Tibetan areas.

\section{Project}

This project is funded by the graduate innovative research project of Southwest Minzu University, "On Human Resources Development in Tibetan Region of Sichuan Province under the Background of Rural Revitalization Strategy" (project number: CX2018SZ144).

\section{Conflicts of Interest}

The author declares no conflicts of interest regarding the publication of this paper.

\section{References}

[1] Gu, M.Y. (1998) The Comprehensive Dictionary of Education. Shanghai Educational Publishing House, Shanghai.

[2] Zhang, S.B. (2009) A Comment on the Frontier Research on the Relationship between Human Capital and Economic Growth in Foreign Countries. Academic Research.

[3] Zha, X.J., Ed. (2007) Information Economics. Tsinghua University Press, Beijing.

[4] Wang, X.C. (2011) On Government Information Resources Management. China Science Publishing \& Media Ltd., Beijing.

[5] Fei, X.T. (2001) On Economy of Jiang Village. The Commercial Press, Beijing.

[6] Wang, S.G. (2012) Tendencies, Causes and Countermeasures of Poverty Changes of Ethnic Minorities. Guizhou Social Sciences, Guiyang.

[7] Cao, T.G. (2013) Diversity and Adaptation: Financial Support and Anti-Poverty in Ethnic Areas. Economist, No. 7, 103-104.

[8] Li, Z.H. (2012) On Empirical Studies on Ethnic and National Identity of Ethnic Groups Living in Frontier Destitute Mountainous Areas-A Case Study of the Lisu Ethic Group. Journal of Yunnan Nationalities University: Social Sciences, 29, 22-26.

[9] Zhou, M.L. (2008) On the Transform of Economic Development in Ethnic Areas. Ethno-National Studies, No. 4, 19-28. 